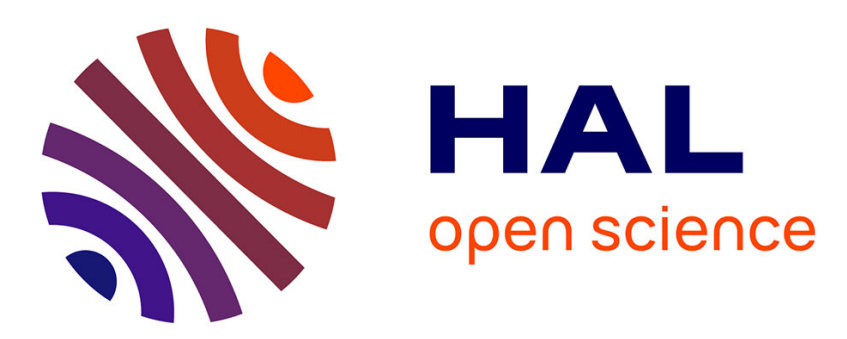

\title{
A STUDY ON THE THERMODYNAMICS AND KINETICS OF TUNGSTEN DEPOSITION BY WF6 AND GeH4
}

\author{
C.A. van Der Jeugd, G. Leusink, G. Janssen, S. Radelaar
}

\section{- To cite this version:}

C.A. van Der Jeugd, G. Leusink, G. Janssen, S. Radelaar. A STUDY ON THE THERMODYNAMICS AND KINETICS OF TUNGSTEN DEPOSITION BY WF6 AND GeH4. Journal de Physique IV Proceedings, 1991, 02 (C2), pp.C2-849-C2-856. 10.1051/jp4:19912101 • jpa-00249779

\section{HAL Id: jpa-00249779 https://hal.science/jpa-00249779}

Submitted on 1 Jan 1991

HAL is a multi-disciplinary open access archive for the deposit and dissemination of scientific research documents, whether they are published or not. The documents may come from teaching and research institutions in France or abroad, or from public or private research centers.
L'archive ouverte pluridisciplinaire HAL, est destinée au dépôt et à la diffusion de documents scientifiques de niveau recherche, publiés ou non, émanant des établissements d'enseignement et de recherche français ou étrangers, des laboratoires publics ou privés. 
Colloque C2, suppl. au Journal de Physique II, Vol 1, septembre 1991

\author{
A STUDY ON THE THERMODYNAMICS AND KINETICS OF TUNGSTEN DEPOSITION \\ BY $\mathrm{WF}_{6}$ AND $\mathrm{GeH}_{4}$
}

\author{
C.A. VAN DER JEUGD, G.J. LEUSINK, G.C.A.M. JANSSEN and \\ S. RADELAAR
}

DIMES, section Submicron Technology, Delft University of Technology, P.O. Box 5046, $2600 \mathrm{GA}$ Delft, The Nederlands

\begin{abstract}
In this paper a thermodynamic and kinetic study of the new deposition process of tungsten on silicon (100) from tungsten hexafluoride $\left(\mathrm{WF}_{6}\right)$ and germane $\left(\mathrm{GeH}_{4}\right)$ is presented. Thermodynamic calculations as well as experiments show, that the reaction occurring during deposition is: $\quad \mathrm{WF}_{6}+3 \mathrm{GeH}_{4} \rightarrow \mathrm{W}+3 \mathrm{GeF}_{2}+6 \mathrm{H}_{2}$

The growth rate as a function of process parameters is obtained for selective depositions in the temperature range from 600 to $800 \mathrm{~K}$, and a total pressure range from 150 to 1000 $m$ Torr. Experiments show that the germane reduction of tungsten hexafluoride is 0.9 order in $\mathrm{WF}_{6},-0.2$ order in $\mathrm{GeH}_{4}$ and zero order in $\mathrm{H}_{2}$. The activation energy is 34 $\mathrm{kJ} / \mathrm{mol}$. These kinetic data of the $\mathrm{GeH}_{4} / \mathrm{WF}_{6}$ process differ markedly from the kinetics of the recently much studied $\mathrm{SiH}_{4} / \mathrm{WF}_{6}$ process.

A fascinating observation is that the deposition rate does not change when $\mathrm{SiH}_{4}$ is added to the $\mathrm{GeH}_{4} / \mathrm{WF}_{6}$ mixture, while, on the contrary, a small amount of $\mathrm{GeH}_{4}$ reduces the growth rate from a $\mathrm{SiH}_{4} / \mathrm{WF}_{6}$ mixture considerably. The kinetic differences between the at first sight similar $\mathrm{GeH}_{4} / \mathrm{WF}_{6}$ and $\mathrm{SiH}_{4} / \mathrm{WF}_{6}$ process are used to get a better insight in both processes.
\end{abstract}

\title{
I Introduction
}

The need for high-density Integrated Circuits (IC's) has involved considerable research effort in the metallisation of submicron IC's. One of the most investigated metallisation processes is the deposition of tungsten by Chemical Vapor Deposition (CVD) ${ }^{1}$. This technique is very promising not only, because the tungsten can be used as a low-resistivity shunt material for the gate, but the tungsten is also a good diffusion barrier, which prevents the interdiffusion of Si source- and drain areas with the aluminium metallisation 2 . In some cases $W$ can also be used as an interconnect material between two metallisation levels in a multilevel ULSI circuit. The CVD technique ensures that submicron contact holes can be filled with an excellent stepcoverage and further provides the possibility of selective deposition: i.e. deposition on $\mathrm{Si}$ and not on $\mathrm{SiO}_{2}$. This saves one lithographic step and so increases the efficiency of the fabrication of an IC.

The most commonly used precursor molecule for W-CVD is tungsten hexafluoride (WF6). Because the $\mathrm{WF}_{6}$ molecule does not decompose spontaneously on a tungsten surface, a reductor is needed to strip the fluorine atoms from $\mathrm{WF}_{6}$. Several reductors have been investigated for this purpose. First of all $\mathrm{Si}$ provided by the substrate is a very effective reductor for $\mathrm{WF}_{6}{ }^{3,4,5,6}$. But this 
reaction can only proceed until the selflimiting thickness has been reached, i.e. until the growing tungsten layer shuts off the interaction between the Si substrate and the $\mathrm{WF}_{6}$. To continue deposition, $\mathrm{H}_{2}$ can be used for the reduction of $\mathrm{WF}_{6}\left(\mathrm{H}_{2}\right.$ process) ${ }^{7,8}$. The reduction of $\mathrm{WF}_{6}$ by $\mathrm{H}_{2}$ is a thoroughly investigated process, but still suffers from problems as, silicon consumption of the substrate, encroachment, wormholes, a low deposition rate $(<200 \mathrm{~nm} / \mathrm{min})$, rough layers, and a relatively high deposition temperature $\left(500^{\circ} \mathrm{C}\right)$. To overcome these problems, $\mathrm{SiH}_{4}$ is used, from 1987 on, as a reductor for $\mathrm{WF}_{6}\left(\mathrm{SiH}_{4}\right.$ process) ${ }^{9}$. This process produces, at low temperatures and with a high deposition rate, smooth layers without encroachment or wormholes and limited Si consumption. But the $\mathrm{SiH}_{4}$ process suffers from problems as high contact resistance to $\mathrm{p}^{+} \mathrm{Si}$. 10 , Si incorporation in the tungsten layer ${ }^{11}$, or the formation of tungsten silicides ${ }^{12}$. Moreover the reproducibility of the $\mathrm{SiH}_{4}$ process is very bad due to the strong sensitivity of the growth process on the $\mathrm{SiH}_{4} / \mathrm{WF}_{6}$ partial pressure ratio. Because small changes in process parameters as temperature, total pressure or flow rate can result in unknown changes of the $\mathrm{SiH}_{4} / \mathrm{WF}_{6}$ partial pressure ratio at the wafer surface, it is very difficult to investigate the kinetics of the $\mathrm{SiH}_{4}$ process.

Recently we introduced $\mathrm{GeH}_{4}$ as a reductor for $\mathrm{WF}_{6}\left(\mathrm{GeH}_{4}\right.$ process) ${ }^{13}$. $\mathrm{GeH}_{4}$ is chemically similar to $\mathrm{SiH}_{4}$ but because Ge does not dissolve in $\alpha-\mathrm{W}^{14}$ and does not easily form tungsten germanides 15 , we hoped for a process, which would result in $\alpha-W$ films over a larger process window than the $\mathrm{SiH}_{4}$ process. It was found that the $\mathrm{GeH}_{4}$ process yields at temperatures above $\approx$ $500^{\circ} \mathrm{C}$ pure $\alpha-W$ layers while below this temperature also $\beta$-W with the $A 15$ bcc crystal structure is formed. At temperatures below $\pm 400^{\circ} \mathrm{C}$ pure $\beta-W$ is formed which is stabilised by relative large amounts of germanium ( up to $\approx 12$ at. $\% \mathrm{Ge}$ ). One of the most striking differences of this $\mathrm{GeH}_{4}$ process compared to the $\mathrm{SiH}_{4}$ process is however that the growth process is not very sensitive to the $\mathrm{GeH}_{4} / \mathrm{WF}_{6}$ partial pressure ratio. This makes the reproducibility of the $\mathrm{GeH}_{4}$ process far better than the $\mathrm{SiH}_{4}$ process and the investigation of the kinetics of the process easier.

This paper will concentrate on the thermodynamics and kinetics of the chemical vapour deposition of $\mathrm{W}$ from $\mathrm{WF}_{6}$ and $\mathrm{GeH}_{4}$. Where ever possible we will compare the results of the $\mathrm{GeH}_{4}$ process with the results of the $\mathrm{SiH}_{4}$ process in order to get a better understanding of both processes.

\section{Experimental}

Selective depositions were performed in a cold-wall single wafer reactor, which is equipped with a load-lock system. In this reactor the wafers are pressed against a graphite chuck which is heated by lamps. The temperature was controlled by a thermocouple in the graphite chuck. The temperature difference between chuck and wafer was calibrated for all deposition conditions by a thermocouple pasted on the front side of a wafer and by a pyrometer. This ensured a stable and reproducible wafer temperature. For the selective depositions we used $100 \mathrm{~mm}$ p-type (100) Si wafers, covered with thermally grown oxide. After patterning, the total exposed fraction of bare Si was less than $10 \%$. Before deposition the wafers were dipped in dilute buffered HF, rinsed in deionized water and dried by pulling the wafers slowly out of the vapor of boiling isopropyl alcohol. Before deposition the reactor was purged with $\mathrm{Ar}$ and $\mathrm{H}_{2}$ with the wafer at deposition temperature. Effects of the displacement reaction (i.e. the reaction of $\mathrm{WF}_{6}$ with $\mathrm{Si}$ ) were minimized in two ways. Either we let the displacement reaction take place at low temperatures (ensuring a thin $W$ layer) before the $\mathrm{GeH}_{4} / \mathrm{WF}_{6}$ deposition started or we introduced the $\mathrm{GeH}_{4}$ flow in the reactor a few seconds before the $\mathrm{WF}_{6}$ flow. The conversion factor for the reaction gases (mole of reacted gas divided by mole of input gas) was less than $10 \%$. The quality of the process gases was electronic grade. The thickness of the W layers was examined by Scanning Electron Microscopy (SEM), and in situ, by measuring the interference signal of a HeNe laser beam reflected from a W-SiO $\mathrm{S}_{2}$ grating. 


\section{Thermodynamics}

The main stable reaction products which can be expected to form during deposition from $\mathrm{GeH}_{4} / \mathrm{WF}_{6}$ are $\mathrm{W}, \mathrm{GeF}_{2}, \mathrm{GeF}_{4}, \mathrm{HF}$ and $\mathrm{H}_{2}$. With these reaction products the overall reaction can be described with only two variables, $x$ and $y$ :

$\mathrm{WF}_{6}+\mathrm{x} \mathrm{GeH}_{4} \rightarrow \mathrm{W}+\mathrm{y} \mathrm{GeF} 2+(\mathrm{x}-\mathrm{y}) \mathrm{GeF}_{4}+(6+2 \mathrm{y}-4 \mathrm{x}) \mathrm{HF}+(4 \mathrm{x}-\mathrm{y}-3) \mathrm{H}_{2}$

Thermodynamic calculations performed with a computer program based on the Solgasmix program developed by Eriksson 16 showed that, in our temperature and pressure regime $(600-800$ $\mathrm{K}, 150-1000 \mathrm{mTorr})$, the process tends to form as much $\mathrm{GeF}_{2}$ as possible. This means that for each deposited $\mathrm{W}$ atom (which releases six $\mathrm{F}$ atoms) three $\mathrm{GeF}_{2}$ molecules will be formed. To form three $\mathrm{GeF}_{2}$ molecule the process needs also three $\mathrm{GeH}_{4}$ molecules. The $\mathrm{H}$ atoms released by the $\mathrm{GeH}_{4}$ molecule, form $\mathrm{H}_{2}$ molecules because from the original $6 \mathrm{~F}$ atoms there are no fluorine atoms left to form HF. So according to the thermodynamic calculations we can write for the overall reaction:

$\mathrm{WF}_{6}+3 \mathrm{GeH}_{4} \rightarrow \mathrm{W}+3 \mathrm{GeF}_{2}+6 \mathrm{H}_{2} \quad \Delta \mathrm{G}=-830(\mathrm{~kJ} / \mathrm{mol})$ at $700 \mathrm{~K}$

This reaction equation gives, of all possible combinations of $\mathrm{x}$ and $\mathrm{y}$ in equation 1 , the highest gain in Gibb's free energy. The gain in Gibb's energy for this reaction is, as a comparison, plotted together with the $\Delta \mathrm{G}$ of the three most commonly used processes ( $\mathrm{Si}, \mathrm{H}_{2}$ and $\mathrm{SiH}_{4}$ reduction) as a function of temperature in Fig. 1. It can be seen in this figure that the gain in Gibb's free energy for the $\mathrm{GeH}_{4}$ process is higher than the $\Delta \mathrm{G}$ of the $\mathrm{H}_{2}$ process and comparable to the $\Delta \mathrm{G}$ of the Si reduction reaction. So, from a thermodynamic view, the unwanted initial severe Si substrate etching by $W_{6}$, which is characteristic for the $\mathrm{H}_{2}$ process, might be suppressed in the $\mathrm{GeH}_{4}$ process.

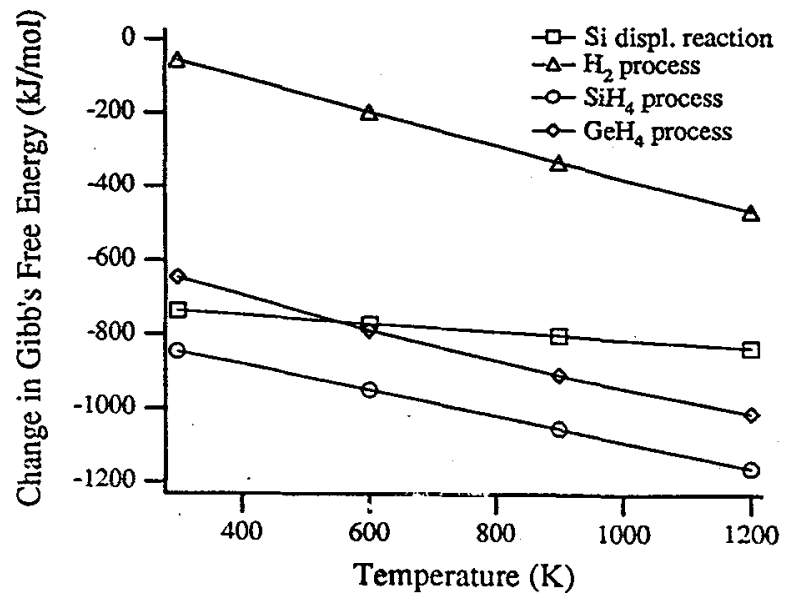

Figure 1. The change in Gibb's free energy as a function of temperature for four deposition processes.

Reaction equation 2 is also checked experimentally by reacting a fixed closed volume of $\mathrm{WF}_{6}$ and $\mathrm{GeH}_{4}$. It was found by mass spectrometry and by measuring the amount of deposited tungsten that, only when the initial $\mathrm{GeH}_{4} / \mathrm{WF}_{6}$ ratio is equal or higher than three (i.e. the stochiometric ratio of equation 2), all $\mathrm{WF}_{6}$ is converted to $\mathrm{W}$. For $\mathrm{GeH}_{4} / \mathrm{WF}_{6}$ ratio's lower than three, part of the $\mathrm{WF}_{6}$ remains unreacted because of depletion of $\mathrm{GeH}_{4}$. The mass spectrometer showed also large amounts of $\mathrm{H}_{2}$ and almost no HF. These experiments support strongly reaction 2 as the main reaction. The total pressure in the fixed volume should, at an initial ratio of $\mathrm{GeH}_{4} / \mathrm{WF}_{6}=3$, increase with a factor $9 / 4$ according to reaction 2 . We observe experimentally only an increase with a factor $6 / 4$. This is because $\mathrm{GeF}_{2}$ condenses on the cold reactor walls which is in accordance with literature 17 . 


\section{Kinetics of the $\mathrm{GeH}_{4}$ process}

The $\mathrm{WF}_{6}$ partial pressure has a strong influence on the deposition rate as is shown in Fig. 2 . In this figure the deposition rate is plotted as a function of the $\mathrm{WF}_{6}$ partial pressure for three different $\mathrm{GeH}_{4}$ partial pressures. The temperature and total pressure are kept constant at $355^{\circ} \mathrm{C}$ and 250 mTorr. The error in the deposition rate is for Fig. 2, but also for the following figures 2 to 7 , estimated on $10 \mathrm{~nm} / \mathrm{min}$. When we average the slopes of the lines representing the dependence of the growth rate on $\mathrm{WF}_{6}$ partial pressure for all three $\mathrm{GeH}_{4}$ partial pressures we find that the averaged slope is 0.9 with a standard deviation of 0.1 . This averaged line is drawn in Fig. 2. Since the results are plotted in Fig. 2 on a double logarithmic scale, the slope of this line represent the order of the reaction with respect to $\mathrm{WF}_{6}$. So the reaction order is 0.9 in $\mathrm{WF}_{6}$ with a standard deviation of 0.1 .

A similar plot is made to determine the order of reaction with respect to $\mathrm{GeH}_{4}$. The result is in Fig. 3 for three different values of the $\mathrm{WF}_{6}$ partial pressure. Temperature and pressure are $355^{\circ} \mathrm{C}$ and 250 mTorr. The drawn lines in Fig. 3 represent the averaged slope for the three $\mathrm{WF}_{6}$ pressures. The reaction order is -0.2 in $\mathrm{GeH}_{4}$ with a standard deviation of 0.1 . The relative large standard deviation is due to the fact that we only varied the $\mathrm{GeH}_{4}$ partial pressure over a small range.

Changing the carrier gas from $\mathrm{H}_{2}$ to Ar did not influence the deposition rate as can be seen in Fig. 4. In this figure the carrier gas was changed from pure Ar via a 1:1 mixture of $\mathrm{Ar}$ and $\mathrm{H}_{2}$ towards pure $\mathrm{H}_{2}$.

The increase in growth rate with the total pressure is shown in Fig. 5 for two different wafer temperatures. The ratio of the partial pressures of $\mathrm{WF}_{6}, \mathrm{GeH}_{4}$, and $\mathrm{H}_{2}$ remained constant at 1:1:50. Because the heat transfer from the chuck to the wafer depends strongly on the total pressure 17 , we adjusted the chuck temperature for every deposition, in order to keep the same wafer temperature over the whole pressure range. We see in Fig. 5 that the order of reaction with respect to the total pressure is 0.7. This corresponds, within the experimental error, to the sum of the dependences on the partial pressures of the source gasses $\mathrm{WF}_{6}, \mathrm{GeH}_{4}$, and $\mathrm{H}_{2}$.

The dependence of the deposition rate on temperature is presented in Fig. 6. The slope of the drawn lines is obtained by averaging the slopes of the Arrhenius plots at each of the three total pressures. The slope of the lines correspond to an activation energy of $34 \mathrm{~kJ} / \mathrm{mol}$ with a standard deviation of $5 \mathrm{~kJ} / \mathrm{mol}$.

With this activation energy and reaction orders we calculated for all our deposition rates the preexponential factor $\mathrm{A}$. This resulted in the following phenomenological rate equation:

in this equation is:

$$
\mathrm{G}=\mathrm{A}\left[\mathrm{WF}_{6}\right]^{0.9}\left[\mathrm{GeH}_{4}\right]^{-0.2} \mathrm{e}^{-34000 / \mathrm{RT}}
$$

G

A

[WF 6 ]

[GeH4]

Activation energy

Gas constant

$\mathrm{T}$ growth rate in $\mathrm{nm} / \mathrm{min}$

$(9 \pm 2) \times 10^{3}$ in $\mathrm{nm} \mathrm{min}^{-1} \mathrm{~m}$ Torr 0.7

WF$_{6}$ partial pressure in mTorr. Exponent is $0.9 \pm 0.1$

$\mathrm{GeH}_{4}$ partial pressure in mTorr. Exponent is $-0.2 \pm 0.1$

$\mathrm{E}_{\mathrm{a}}=(34 \pm 5) \mathrm{kJ} / \mathrm{mol}$

$\mathrm{R}=8.314 \mathrm{~J} / \mathrm{mol} . \mathrm{K}$

Temperature in $\mathrm{K}$

This $\mathrm{GeH}_{4}$ rate equation differs from the $\mathrm{SiH}_{4}$ rate equation which is described in literature 18 as:

$$
\mathrm{G}=\text { Constant }\left[\mathrm{SiH}_{4}\right]
$$




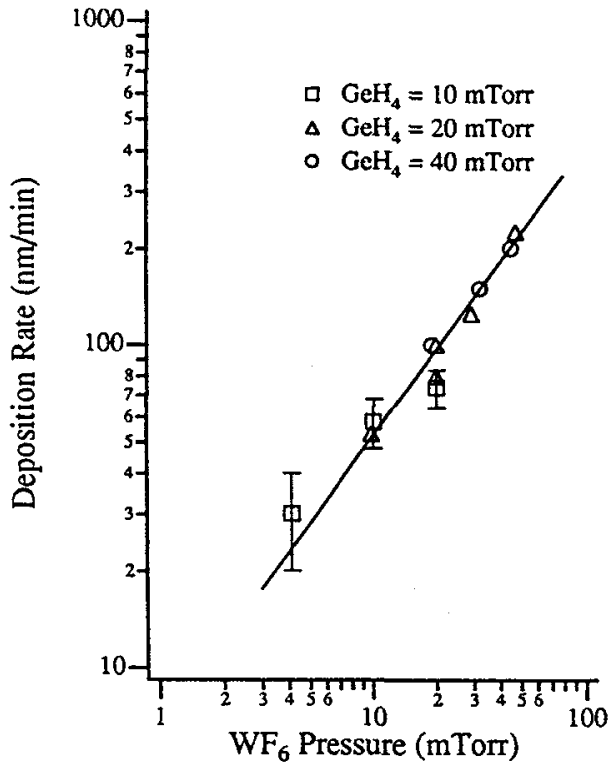

Figure 2. Growth rate as a function of $\mathrm{WF}_{6}$ partial pressure for three different $\mathrm{GeH}_{4}$ partial pressures. The slope of the line is $0.9 \pm 0.1$.

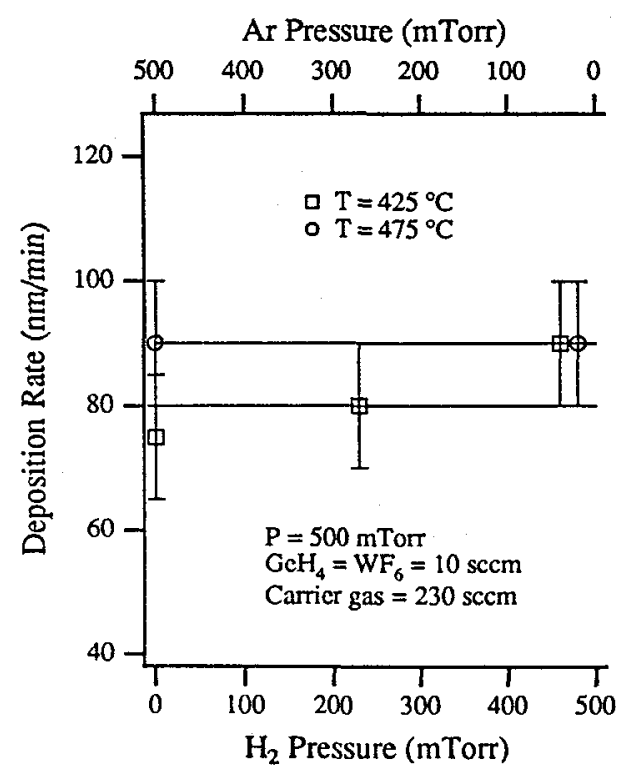

Figure 4. Growth rate as a function of $\mathrm{H}_{2}$ and Ar partial pressure for two temperatures.

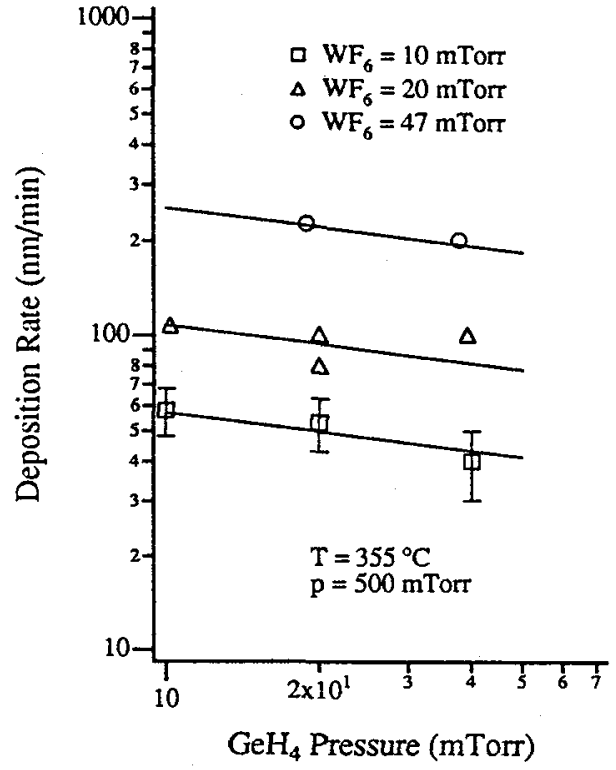

Figure 3. Growth rate as a function of $\mathrm{GeH}_{4}$ partial pressure for three different $W_{6}$ partial pressures. The slope of the lines is $-0.2 \pm 0.1$.

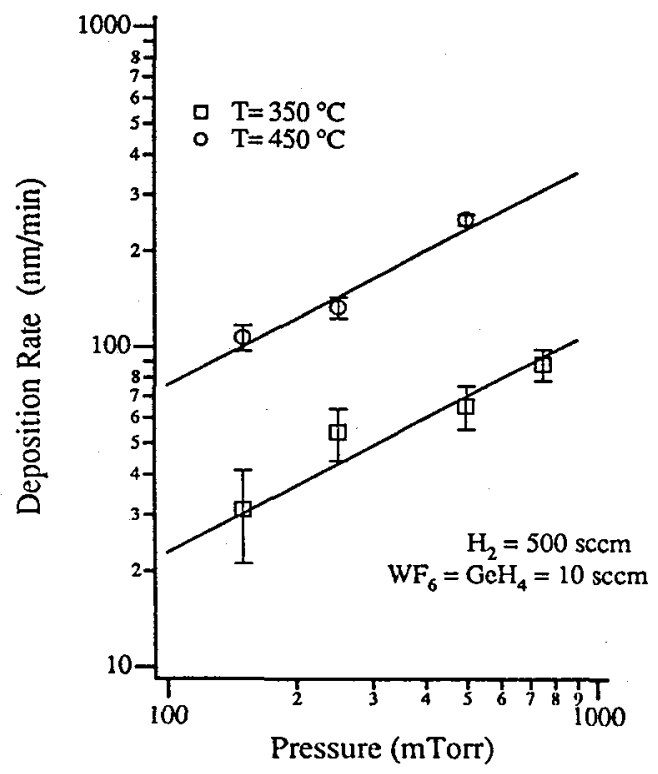

Figure 5. Growth rate as a function of total pressure for two temperatures. The slope of the lines is 0.7 


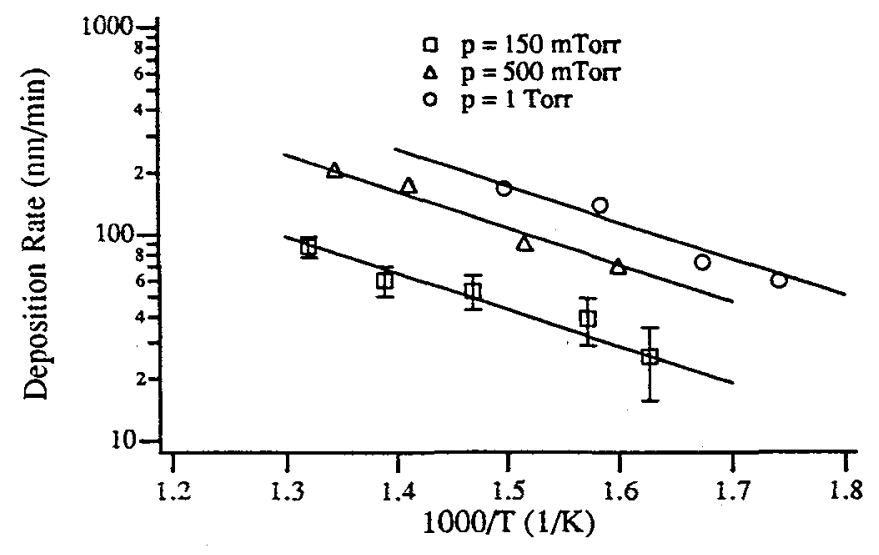

Figure 6. Growth rate as a function of temperature for three different total pressures.

\section{Mixing of the reductors $\mathrm{SiH}_{4}$ and $\mathrm{GeH}_{4}$}

In order to learn more about the $\mathrm{GeH}_{4} / \mathrm{WF}_{6}$ but also about the $\mathrm{SiH}_{4} / \mathrm{WF}_{6}$ deposition process we performed experiments in which we mixed the reductors $\mathrm{GeH}_{4}$ and $\mathrm{SiH}_{4}$. The results are in Fig. 7a and $7 \mathrm{~b}$. First we kept the $\mathrm{GeH}_{4}$ and $\mathrm{WF}_{6}$ flow constant and added some $\mathrm{SiH}_{4}$ to the process. The result, which is in Fig. $7 \mathrm{a}$, shows the $\mathrm{W}$ deposition rate as a function of the $\mathrm{SiH}_{4}$ flow which was added to the $\mathrm{GeH}_{4} / \mathrm{WF}_{6} / \mathrm{H}_{2}$ flow. It is clear from Fig. $7 \mathrm{a}$ that the influence of the $\mathrm{SiH}_{4}$ flow is negligible. This is surprising since the $\mathrm{SiH}_{4}$ process would give under these process conditions a higher deposition rate. This is shown in Fig. $7 \mathrm{~b}$. Here the $\mathrm{W}$ growth rate of the $\mathrm{SiH}_{4}$ process is plotted as a function of the added $\mathrm{GeH}_{4}$ flow. It can be seen in this figure that the growth rate drops significantly from $250 \mathrm{~nm} / \mathrm{min}$ for a pure $\mathrm{SiH}_{4}$ process to $\pm 60 \mathrm{~nm} / \mathrm{min}$ when $\mathrm{GeH}_{4}$ is added to the process.

These experiments show clearly that, in a mixture of $\mathrm{SiH}_{4}$ and $\mathrm{GeH}_{4}$, the kinetics of the $\mathrm{GeH}_{4}$ deposition of $\mathrm{W}$ control the overall deposition process.
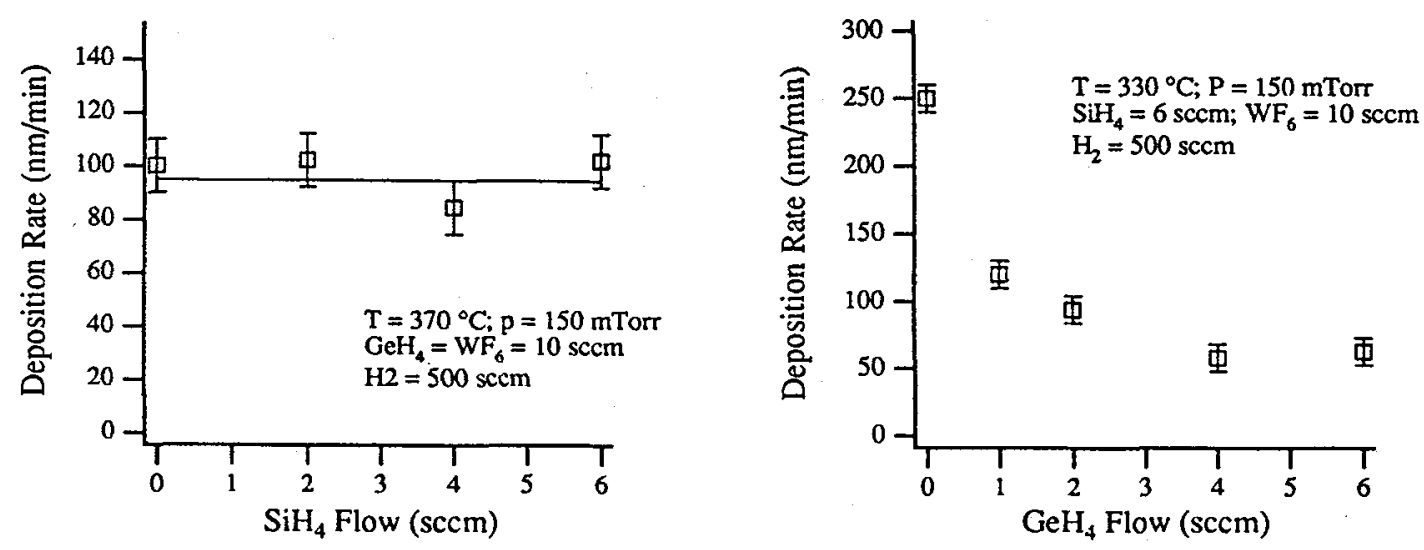

Figure 7. Growth rate for a mixture of the reductors $\mathrm{GeH}_{4}$ and $\mathrm{SiH}_{4}$. a) $\mathrm{SiH}_{4}$ added to the $\mathrm{GeH}_{4}$ process and b) $\mathrm{GeH}_{4}$ added to the $\mathrm{SiH}_{4}$ process. 


\section{Discussion}

The rate equation of the $\mathrm{GeH}_{4}$ process (3) differs significantly from the rate equation of the $\mathrm{SiH}_{4}$ process (4), which is linear in $\mathrm{SiH}_{4}$ pressure and independent of the WF 6 pressure. The activation energy of the $\mathrm{GeH}_{4}$ process shows a well defined value of $34 \mathrm{~kJ} / \mathrm{mol}$ in contrast to the unclear low activation energy of the $\mathrm{SiH}_{4}$ process. So, although the $\mathrm{SiH}_{4}$ and the $\mathrm{GeH}_{4}$ process look at first sight rather similar, the deposition processes are obviously controlled by different rate limiting steps.

The kinetics of the $\mathrm{SiH}_{4}$ process is described in literature by $\mathrm{Yu}$ and Eldridge ${ }^{19}$ as a continuous sequence of two steps. One step is the decomposition of $\mathrm{SiH}_{4}$ to $\mathrm{Si}$. The second step is the deposition of $\mathrm{W}$ by reducing $\mathrm{WF}_{6}$ with this silicon. When we apply this model also to the $\mathrm{GeH}_{4} / \mathrm{WF}_{6}$ process we can compare the $\mathrm{GeH}_{4}$ decomposition with the $\mathrm{SiH}_{4}$ decomposition and the consecutive step i.e. the reaction of $\mathrm{WF}_{6}$ with $\mathrm{Ge}$ to form $\mathrm{W}$ and $\mathrm{GeF}_{2}$ can than be compared with the Si reduction reaction of $\mathrm{WF}_{6}$ to form $\mathrm{W}$ and $\mathrm{SiF}_{4}$.

Our experiment described in Section $\mathrm{V}$ with the $\mathrm{SiH}_{4} / \mathrm{GeH}_{4} / \mathrm{WF}_{6}$ mixture showed that in this mixture the $\mathrm{GeH}_{4}$ process controls completely the deposition process. This suggests strongly that the surface is covered with $\mathrm{GeH}_{\mathrm{x}}$ fragments and not with $\mathrm{SiH}_{\mathrm{x}}$. This implies that, under same conditions, the adsorption and decomposition is faster for $\mathrm{GeH}_{4}$ than for $\mathrm{SiH}_{4}$. This agrees with results from literature that $\mathrm{Ge}$ layers can be grown from $\mathrm{GeH}_{4}$ at considerable lower temperatures than Si layers from $\mathrm{SiH}_{4}$.

For the $\mathrm{WF}_{6}$ reduction step the reaction rate of $\mathrm{WF}_{6}$ with $\mathrm{Si}$ to form $\mathrm{SiF}_{4}$ is known to be very fast. At present no data is available about the reaction rate of $\mathrm{WF}_{6}$ with $\mathrm{Ge}$, but it is likely that this reaction is not as fast as the $\mathrm{Si}$ reduction reaction.

So when we apply the concept of the continuous deposition sequence of the $\mathrm{SiH}_{4}$ process also to the $\mathrm{GeH}_{4}$ process then the clear differences in the kinetics of these two processes can probably be explained as follows. In the $\mathrm{SiH}_{4}$ process the ratelimiting mechanism is the adsorption and/or decomposition of $\mathrm{SiH}_{4}$ while the surface reaction of $\mathrm{WF}_{6}$ with $\mathrm{Si}$ is fast. In the $\mathrm{GeH}_{4}$ process the adsorption and decomposition of $\mathrm{GeH}_{4}$ is fast while the ratelimiting mechanism is the surface reaction between adsorped $\mathrm{Ge}$ and $\mathrm{WF}_{6}$ to $\mathrm{W}_{\text {and }} \mathrm{GeF}_{2}$.

\section{Conclusions}

We conclude from thermodynamic calculations as well as from experiments that the deposition of $\mathrm{W}$ from $\mathrm{WF}_{6}$ and $\mathrm{GeH}_{4}$ proceeds according to the following reaction equation:

$\mathrm{WF}_{6}+3 \mathrm{GeH}_{4} \rightarrow \mathrm{W}+3 \mathrm{GeF}_{2}+6 \mathrm{H}_{2}$

$\Delta \mathrm{G}=-830(\mathrm{~kJ} / \mathrm{mol})$ at $700 \mathrm{~K}$

The formed $\mathrm{GeF}_{2}$ deposits on the cold walls of the reactor.

The deposition rate is described by the following equation:

$\mathrm{G}(\mathrm{nm} / \mathrm{min})=9 \times 10^{3}\left[\mathrm{WF}_{6}(\mathrm{mT} \text { Torr })\right]^{0.9}\left[\mathrm{GeH}_{4}(\mathrm{mTor})\right]^{-0.2} \exp \frac{-34(\mathrm{~kJ} / \mathrm{mol})}{\mathrm{RT}}$

This rate equation differs clearly from the rate equation of the $\mathrm{SiH}_{4}$ process and shows that these processes are controlled by different rate limiting steps. It is proposed that in the $\mathrm{GeH}_{4} / \mathrm{WF}_{6}$ process the surface reaction between adsorped $\mathrm{Ge}$ and $\mathrm{WF}_{6}$ is rate limiting. 


\section{Acknowledgements}

This work is part of the research program of the IOP - IC and the "Stichting voor Fundamenteel Onderzoek der Materie (FOM)", which is financially supported by the "Nederlandse Organisatie voor Wetenschappelijk Onderzoek (NWO)". We like to thank professor S. Wagner for pointing out reference 17 to us. We further thank T.G.M. Oosterlaken, Z.A. Ruchadze and J. Tóth for help in performing the experiments.

\section{References}

[1] See for instance the proceedings of the « Workshops on Tungsten and Other Refractory Metals for VLSI Applications I to V », ( Materials Research Society, Pittsburgh, PA )

[2] BLEWER R.S., Solid State Technol. 29, (1986) 117

[3] BUSTA H.H. and TANG C.H., J. Electrochem. Soc. 133, (1986) 1195

[4] GREEN M.L., Ali Y.S., BOONE T., DAVIDSON B.A., FELDMAN L.C. and NAKAhaRA S., $J$. Electrochem. Soc. 134, (1987) 2285

[5] KUIPER A.E.T., WILlEMSEN M.F.C. and SCHMITZ J.E.J., Appl. Surf. Sci. 38, (1989) 338

[6] LEUSINK G.J., HEERKENS C.Th.H., JANSSEN G.C.A.M. and RADELAAR S., to be published in the proceeding of the « MRS 1990 Fall Meeting », ( Materials Research Society, Pittsburgh, PA )

[7] BROADBENT E.K. and RAMILLER C.L., J. Electrochem. Soc. 131, (1984) 1427

[8] MCCONICA C.M. and KRISHNAMANI K., J. Electrochem. Soc. 133, (1986) 2542

[9] KUSUMOTO Y., TAKAKUWA K., HASHINOKUCHI H., IKUTA T. and NAKAYAMA I., in Tungsten and Other Refractory Metals for VLSI Applications III, edited by V.A. WELLS ( Materials Research Society, Pittsburgh, PA, 1988), p. 103.

[10] HAMMAR M., ZHANG S.L., BUCHTA R. and JOHANSSON T., Thin Solid Films, 185, (1990) 9

[11] VAN DER JEUGD C.A., VERBRUGGEN A.H., LEUSINK G.J., JANSSEN G.C.A.M. and RADELAAR S., Mater. Res. Soc. Symp. Proc. 168, (1990) 179

[12] SCHMITZ J.E.J., BUITING M.J. and ELLWANGER R.C. in Tungsten and other Refractory Metals for VLSI Applications IV, edited by BLEWER R.S. and MCCONICA C.M., (Materials Research Society, Pittsburgh, PA, 1989), p. 27.

[13] VAN DER JEUGD C.A., LEUSINK G.J., JANSSEN G.C.A.M. and RADELAAR S., Appl. Phys. Lett. 57, (1990) 354

[14] NOWOTNY H., BENESOVSKY F. and BRUKL C., Monatshefte für Chemie 92, (1961) 365

[15] POPOVA S.V. and FOMICHEVA L.N., Inorg. Mater. (Engl. Transl.), 14, (1978) 533

[16] ERIKSSON G., Chem. Scr. 8, (1975) 100

[17] Slobodin D., AlJiShi S. and WAGNER S., Mater. Res. Soc. Symp. Proc. 98, (1987) 291

[18] SCHMITZ J.E.J., SUIJKER J.L.G. and BUITING M.J., in Tungsten and Other Refractory Metals for VLSI Applications IV, edited by BLEWER R.S. and MCCONICA C.M., ( Materials Research Society, Pittsburgh, PA, 1989), p. 211.

[19] YU M.L. and ELDRIDGE B.N., J. Vac. Sci. Technol. A 7, (1989) 625 